\title{
O desenvolvimento dos municípios da microrregião de São João del-Rei/MG: uma análise para o período $2005 / 2015$
}

\author{
Sinara da Silva Anastácio ${ }^{1}$ \\ Norberto Martins Vieira ${ }^{2}$ \\ Thiago Periard do $\mathrm{Amaral}^{3}$
}

\begin{abstract}
RESUMO
O presente trabalho analisou o desenvolvimento municipal da microrregião de São João del-Rei - MG, considerando os anos compreendidos entre 2005 e 2015. Para isso, por meio do IFDM, foi estudada a evolução dos indicadores municipais de emprego, renda, saúde e educação e buscou-se identificar se a melhora ocorrida em determinado município se deu pela adoção de políticas públicas ou pela ascensão da microrregião como um todo. Foi constatada, em relação ao desenvolvimento dos municípios, uma tendência de perpetuação da pobreza naqueles com menor renda e da riqueza nas regiões mais prósperas. O mais preocupante é que a diferença entre o PIB per capita dos municípios mais ricos e o dos municípios mais pobres se tornou maior, sugerindo, então, que há uma espécie de Causação Circular Cumulativa agindo sobre eles. Os municípios que estavam em Círculo Vicioso ou com indicadores sociais defasados, como é o caso de Prados, Santa Cruz de Minas e Tiradentes, tiveram dificuldades de mudar sua situação; enquanto os que se mostraram prósperos, com indicadores sociais e econômicos acima da média microrregional, tenderam a se manter em boa posição (Dores de Campos e Nazareno). O entendimento da dinâmica socioeconômica nesses municípios pode ser útil para o desenvolvimento de políticas públicas mais eficientes, de forma que estas tragam o máximo de benefícios possíveis para essa localidade.
\end{abstract}

Palavras-chave: Desenvolvimento municipal. IFDM. Causação Circular Cumulativa.

\section{The development of the municipalities of the São João del-Rei/MG micro-region: an analysis for the period $2005 / 2015$}

\begin{abstract}
The present work analyzed the municipal development of the São João del-Rei - MG micro-region, considering the years between 2005 and 2015. For this purpose, through the IFDM, the evolution of the municipal indicators of employment, income, health and education was studied, and it sought to identify whether the improvement that occurred in a given municipality was due to the adoption of public policies or the rise of the micro-region as a whole. In relation to the development of the municipalities, a tendency to perpetuate poverty was found in those with lower income and wealth in the most prosperous regions. Most worrying is that the difference between the GDP per capita of the richest municipalities and that of the poorest municipalities has become greater, suggesting, then, that there is a kind of Circular Cumulative Causation acting on them. The municipalities that were in a Vicious Circle or with outdated social indicators, such as Prados, Santa Cruz de Minas and Tiradentes, had difficulties to change their situation; while those who were prosperous, with social and economic indicators above the microregional average, tended to remain in good standing (Dores de Campos and Nazareno). Understanding the socioeconomic dynamics in these municipalities can be useful for the development of more efficient public policies, so that they bring the maximum benefits possible to that location.
\end{abstract}

Keywords: Municipal development. IFDM. Circular cumulative causation.

\section{INTRODUÇÃO}

O desenvolvimento econômico de um país ou estado-nação pode ser definido como o processo de acumulação de capital e incorporação de progresso técnico ao trabalho e ao capital,

\footnotetext{
${ }^{1}$ Graduada em Ciências Econômicas na Universidade Federal de São João del-Rei (UFSJ); mestranda em Economia na Universidade Federal de Viçosa (UFV).

${ }^{2}$ Professor do Departamento de Ciências Econômicas (UFSJ). Email norbertovieira@ufsj.edu.br

${ }^{3}$ Professor do Departamento de Ciências Econômicas (UFSJ).
} 
o qual leva ao aumento da produtividade, dos salários e do padrão médio de vida da população (BRESSER-PEREIRA, 2008). É importante que esse desenvolvimento supra o objetivo político fundamental das sociedades modernas - o bem-estar -, de forma que apresente melhorias nos aspectos relacionados à qualidade de vida, educação, saúde e infraestrutura.

Nos últimos quarenta anos, o termo "desenvolvimento" deixou de denotar estritamente fenômenos e processos econômicos - tais como o aumento do produto real per capita ou o aumento da produtividade dos fatores de produção - e passou a incorporar, também, novas expressões associadas ao desenvolvimento, como "desenvolvimento sustentável" e "desenvolvimento humano" (PNUD, 2019).

Segundo as Nações Unidas (2019), o desenvolvimento econômico destina-se a oferecer aos povos melhores oportunidades para uma vida mais condigna. É necessário, além do aumento do produto, o estabelecimento de políticas públicas para alcançar melhorias sociais. Dessa forma, a condição essencial para o desenvolvimento consiste no suprimento de necessidades básicas das pessoas: nutrição, educação, emprego, distribuição da renda e oportunidades iguais. Assume-se, então, que o desenvolvimento é um processo de transformação estrutural no qual os indivíduos participam e vivenciam os resultados, o que implica, necessariamente, na elevação da qualidade de vida geral.

Enquanto colaborador na criação do Índice de Desenvolvimento Humano (IDH), o pensamento de Amartya Sen se colocou como alternativa para analisar e explicar o desenvolvimento das regiões e dos países. Criado em 1990 por Mahbub ul Haqcom, o objetivo do IDH é ser uma medida geral do desenvolvimento humano, pois, além de computar o PIB per capita - e corrigi-lo pelo poder de compra da moeda de cada país -, ele também leva em conta a educação e a longevidade da população (PNUD, 2019).

A partir de categorias associadas ao conceito de desenvolvimento humano usado por Sen - renda, saúde e educação -, a Federação da Indústria do Rio de Janeiro (Firjan) desenvolveu o Índice Firjan de Desenvolvimento Municipal (IFDM), que tem como objetivo medir o desenvolvimento dos municípios brasileiros. O IFDM é muito semelhante ao IDH, porém eles possuem uma diferença primordial: enquanto os dados do IFDM podem ser coletados todo ano, os do IDH só podem ser levantados uma vez por década, já que estes dependem de dados do censo demográfico, realizado a cada 10 anos (FIRJAN, 2018a).

A análise do desenvolvimento municipal da microrregião mineira de São João del-Rei poderá servir para uma melhor compreensão de como as dimensões econômicas - emprego e renda - e sociais - saúde e educação - contribuem para os IFDMs estudados. O presente trabalho buscou responder à seguinte indagação: Houve desenvolvimento municipal na microrregião de São João del-Rei - MG ao longo do período 2005/2015? É esperado que os municípios que efetuam maiores transferências públicas referentes à saúde e à educação sejam mais desenvolvidos.

Esse artigo está estruturado em cinco tópicos. Após essa introdução, foi feita a apresentação dos procedimentos metodológicos. Um breve relato sobre a formação histórica dos municípios da microrregião de São João del-Rei é feita no tópico 3. Os resultados e discussão são apresentados e discutidos no tópico 4. Por fim, no tópico 5, são apresentadas as conclusões na pesquisa.

\section{PROCEDIMENTOS METODOLÓGICOS}

O trabalho analisou o desenvolvimento municipal da microrregião de São João del-Rei MG, considerando os anos compreendidos entre 2005 e 2015. Os dados foram obtidos nas fontes mencionadas abaixo: 
- Federação das Indústrias do Estado do Rio de Janeiro (Firjan): Foram extraídos os IFDMs dos municípios para os anos de 2005 e 2015 (IFDM, 2019);

- Tesouro Nacional: Do relatório emitido pela Finanças do Brasil (Finbra) foram recolhidas informações sobre transferências públicas referentes à saúde e à educação e a população de cada município (Tesouro Nacional, 2019);

- Instituto Brasileiro de Geografia e Estatísticas (IBGE): A partir do site do IBGE, as estimativas referentes ao PIB per capita foram recolhidas, uma vez que estas são intimamente ligadas aos componentes emprego e renda do IFDM (IBGE, 2016);

Primeiramente foi estudada a evolução dos indicadores municipais de emprego, renda, saúde e educação por meio do IFDM. Através de cartografia, foram identificados e analisados os estágios de desenvolvimento dos municípios. Ainda, para identificar se há uma causação circular cumulativa agindo sobre os municípios, foi adaptada a metodologia do Informe sobre Desarrollo - México, publicada pela PNUD (2003). No estudo, as unidades federativas do México foram separadas de acordo com seu perfil de desenvolvimento (IDHM), seguindo a classificação abaixo:

- Círculo Vicioso: PIB per capita, longevidade e conhecimento apresentando piores resultados que a média nacional;

- Tendência ao Crescimento: PIB per capita acima da média nacional, mas não os indicadores sociais (longevidade e/ou conhecimento);

- Tendência Desenvolvimento: PIB per capita abaixo da média nacional, mas o índice de longevidade e/ou do conhecimento com valores acima do valor médio;

- Círculo Virtuoso: PIB per capita, longevidade e conhecimento apresentando melhores resultados que a média nacional.

Como a área de estudo dessa pesquisa é a microrregião de São João del-Rei, serão estes os valores médios usados como referência ao definir o perfil de desenvolvimento. Outra diferença primordial desta metodologia para àquela utilizada no Informe sobre Desarrollo Humano, são os indicadores sociais que, nesse caso, são os referentes à educação e saúde do IFDM.

\section{BREVE RELATO SOBRE A FORMAÇÃO HISTÓRICA}

A região de São Joao del-Rei tem uma longa história que reflete os próprios ciclos de crescimento do país. "Descoberta" entre o final do século XVII e início do século XVIII no ciclo de interiorização do país conhecido como o período das bandeiras e entradas. As bandeiras e entradas vão obter o auge do sucesso quando encontram ouro na região da cidade de São João del-Rei. Com o declínio do ouro, na final do século XVIII a região vai assumir uma vocação mais agrícola, sem no entanto se caracterizar pela monocultura de exportação. Devido à implementação dos polos urbanos na época do ouro, a região manteve um caráter mais urbano do que o que havia se desenvolvido na área de exploração da cana no nordeste brasileiro.

No final do século XIX a cidade começa se a modernizar, com a chegada da ferrovia e as primeiras tentativas de industrialização. No século XX se intensifica a atividade industrial na região, mas cada vez mais voltada à exportação de minérios. A partir dos anos de 1930 o crescimento populacional passa a ser mais intenso, o que vai expandir consideravelmente a área de ocupação territorial da cidade.

Esse crescimento populacional leva a cidade a se confirmar como um polo regional de serviços, sendo a principal referência na região para o comércio, para os serviços de saúde e 
educação. Desta maneira, o estudo da região de São João delirei oferece uma oportunidade de compreender não somente a história local, mas como essa história reflete o contexto nacional.

O antigo Arraial Novo do Rio das Mortes, que deu origem ao município de São João delRei, tem sua origem remontada a 1704, quando o paulista Lourenço Costa descobriu ouro no ribeirão de São Francisco Xavier, ao norte da encosta da Serra do Lenheiro. Pouco tempo depois, o português Manoel José de Barcelos encontrou ouro, também, na encosta sul da Serra do Lenheiro, onde se fixou, a partir daí, o primeiro núcleo de povoamento que daria origem ao Arraial Novo de Nossa Senhora do Pilar, mais tarde Arraial Novo do Rio das Mortes (IBGE, 1959). Como outros arraiais mineradores, o povoado surgiu em torno de uma capela, que, nessa localidade, era em devoção à Nossa Senhora do Pilar. Atraídos pelo ouro, bandeirantes e aventureiros foram se fixando na região, aumentando, a cada dia, a aglomeração de moradias e capelas.

Em 1713, o Arraial Novo do Rio das Mortes já era bastante próspero, de forma que chegou a ser elevado a vila, recebendo o nome de São João del-Rei, em homenagem a Dom João V, rei de Portugal. Desde os seus tempos de formação, a área desenvolveu uma vasta produção mercantil e de gêneros alimentícios, resultantes tanto da atividade agrícola, quanto da pecuária. Isso possibilitou o contínuo crescimento da localidade, que não sofreu grandes perdas com o declínio da retirada de ouro, chegando, inclusive, a se tornar a cidade mais rica de Minas Gerais na primeira metade do século XIX (PEREIRA, 2009, p. 9).

Em 1838, a Vila de São João del-Rei tornou-se município. Nessa época, possuía cerca de 1.600 casas, distribuídas em 24 ruas e 10 praças. O desenvolvimento do município se acelerou, ainda mais, com a inauguração, em 1881, da primeira seção da Estrada de Ferro Oeste-Minas, ligando as cidades da região a outros importantes ramais da Estrada de Ferro Central do Brasil (SANTOS, p. 27, 2017).

Em 1893, a instalação da Companhia Industrial São-Joanense de Fiação e Tecelagem trouxe novo impulso à economia local, a tal ponto que a cidade foi novamente indicada para sediar a capital de Minas Gerais. Em dezembro de 1893, porém, o Congresso Mineiro Constituinte decidiu que a capital mineira seria instalada na região do Curral del-Rei, atual Belo Horizonte (MINAS GERAIS, 2019). Após essa determinação, São João del-Rei diminuiu substancialmente sua importância econômica, mas seu estoque de materialidades históricas herdado do período colonial fez com que sua relevância turística só crescesse ao longo dos anos. A cidade é formada por uma mescla de estilos arquitetônicos fundamentados na arte barroca, passando pelo ecletismo e chegando ao moderno. Seu acervo arquitetônico e artístico, em 1938, foi tombado pelo Instituto do Patrimônio Histórico e Artístico Nacional (IPHAN, 2014).

Atualmente, a microrregião de São João del-Rei não constitui um polo altamente industrializado, possuindo como destaque as atividades de agricultura, artesanato e turismo, e hotelaria. Enquanto nos municípios de Ritápolis, Dores de Campos, Piedade do Rio Grande se destacam a agricultura e a produção de leite e derivados, nos municípios de Tiradentes, Resende Costa e Prados os setores mais importantes são o de turismo e hotelaria, e o de artesanato (FERREIRA JÚNIOR, BAPTISTA, LIMA, 2004, p. 56).

São João del-Rei foi o primeiro da microrregião a ter adquirido o título de município. Atualmente possuiu grande representatividade na produção agropecuária microrregional, sendo isso relacionado à sua vasta produção agrícola de milho, feijão, arroz, soja, café, laranja e outros. Já Tiradentes possui tradição no setor de turismo. Santa Cruz de Minas, em 1995, foi emancipado de Tiradentes, sendo, então, o último da região a adquirir denominação de município. A agricultura é o setor menos relevante da sua economia e, em extensão, ele é o menor município brasileiro, com 3,565 quilômetros quadrados (IBGE, 2018).

A principal característica da maioria dos municípios da microrregião é a sua posição histórica. O garimpo de ouro e pedras preciosas, que começou no município de São João del-Rei, 
foi a primeira atividade determinante na formação de seus aglomerados - arraiais, povoados e vilas.

Em alguns locais, mesmo que a mineração não tenha sido a causa direta da fixação populacional, como é o caso de Madre de Deus de Minas, Resende Costa e Ritápolis, o desenvolvimento do povoado se deu, principalmente, por passantes vindos de municípios mineradores vizinhos. São João del-Rei se destaca por sua orientação comercial, sendo considerada cidade-polo desde a sua constituição.

Tiradentes, por sua vez, teve grande importância no movimento da inconfidência mineira, e hoje é destino turístico de grande relevância nacional. Infere-se que a atividade extrativa foi fundamental para sustentar a economia da microrregião durante o processo de desenvolvimento das vilas, gerando grande crescimento populacional e importantes manifestações políticas, sociais e culturais (UFSJ, 2007).

\section{RESULTADOS E DISCUSSÃO}

\subsection{ANÁLISE DO ÍNDICE FIRJAN DE DESENVOLVIMENTO MUNICIPAL}

Criado pelo Sistema da Federação das Indústrias do Estado do Rio de Janeiro (Firjan), o IFDM acompanha o desenvolvimento dos mais de cinco mil municípios brasileiros em três áreas: emprego e renda, educação e saúde. Ele é constituído exclusivamente de dados de estatísticas públicas oficiais, disponibilizadas pelos ministérios do Trabalho, Educação e Saúde. Atualmente ele representa uma importante fonte de informação na definição de políticas públicas e investimentos entre os municípios brasileiros, pois ele não só demonstra a conjuntura econômico-social do local, como considera os esforços envolvidos na busca de melhores resultados (ERVILHA; ALVES; GOMES, 2013, p. 106).

Segundo a sua metodologia, o índice varia de 0 (mínimo) a 1 ponto (máximo), tendo o grau de desenvolvimento do município seguindo a seguinte classificação:

a) municípios com IFDM entre zero e 0,4 ponto: baixo desenvolvimento;

b) municípios com IFDM entre 0,4 e 0,6 ponto: desenvolvimento regular;

c) municípios com IFDM entre 0,6 e 0,8 ponto: desenvolvimento moderado;

d) municípios com IFDM superior a 0,8: alto estágio de desenvolvimento.

Os indicadores de emprego e renda, educação e saúde possuem a mesma ponderação no cálculo do IFDM, sendo o índice a média aritmética simples destas três dimensões.

Para facilitar a visualização dos resultados, mapas foram elaborados pelo programa QGis para demonstrar a evolução do índice para os anos de 2005, 2010 e 2015. O Índice Firjan é originalmente classificado em 4 níveis de desenvolvimento, mas, nos mapas, utilizou-se uma nova divisão para explicitar as diferenças regionais. Esse recorte não altera a estrutura original, apenas aumenta a sensibilidade das mudanças dentro do IFDM.

De modo geral, houve melhoria no nível de desenvolvimento de toda a microrregião estudada, dado que nenhum município chegou ao ano de 2015 com um índice pior do que o observado em 2005. Além disso, desde 2005, não foi registrado nenhum caso de baixo desenvolvimento, segundo o índice Firjan. O menor valor encontrado foi em 2005, no município de Conceição da Barra de Minas - 0,4995 -, e o maior em Coronel Xavier Chaves, no ano de $2010-0,7669$ (Figura 1). 
Figura 1 - Microrregião de São João del-Rei no ano de 2005, 2010 e 2015, de acordo com o seu IFDM

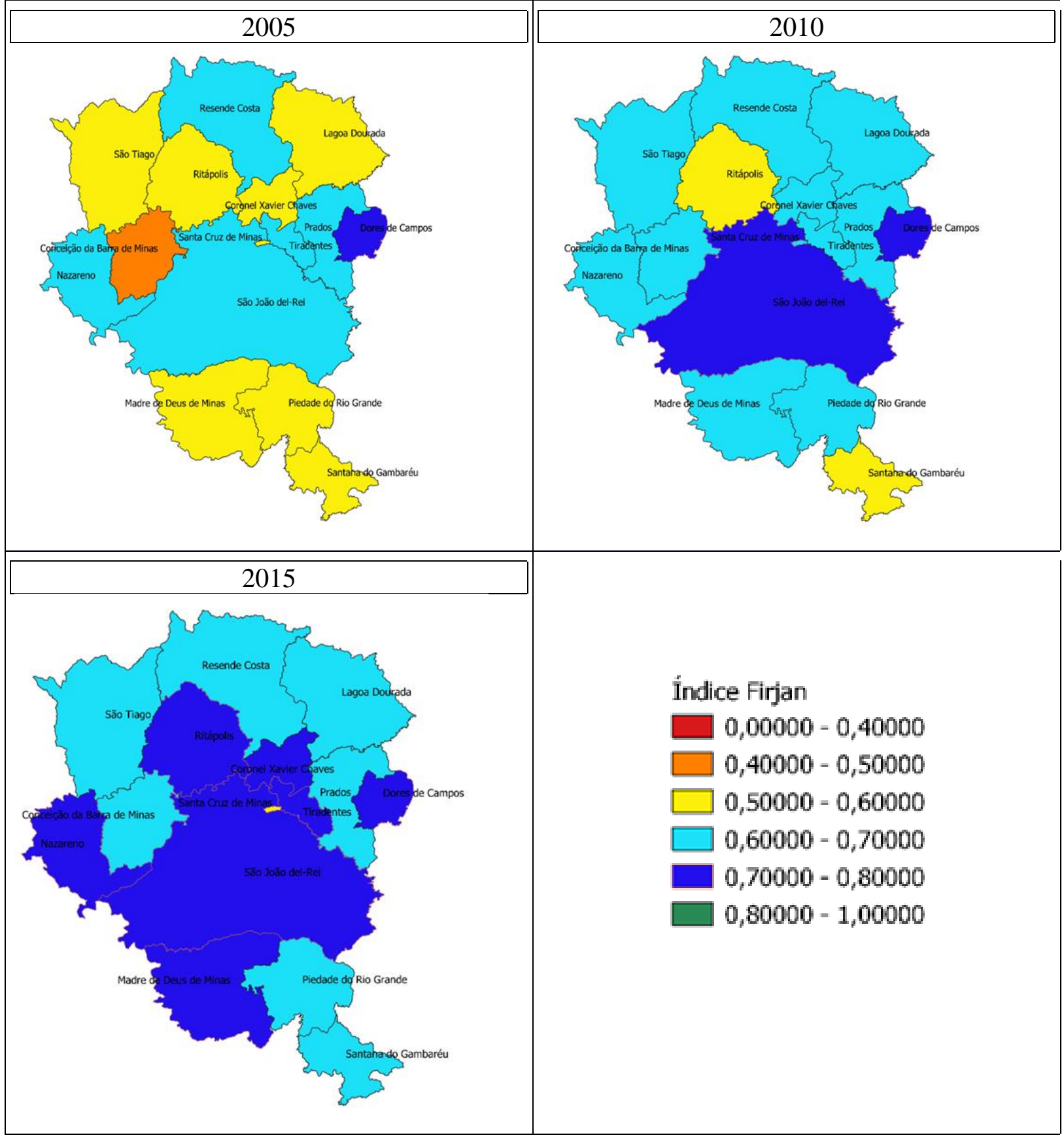

Fonte: Elaborado no programa QGis, a partir de dados da Firjan (2019).

Em 2005, a maioria dos municípios apresentava desenvolvimento regular, isto é, IFDM compreendido entre 0,400 e 0,600. Em 2010, contudo, a situação se inverteu: apenas os municípios de Ritápolis e Santana do Gambaréu não manifestaram desenvolvimento moderado. Já no ano final de análise, 2015, todos os municípios, com exceção de Santa Cruz de Minas, fecharam com índice superior a 0.600 .

O município de Santa Cruz de Minas começou o período de estudo relativamente bem (IFDM igual a 0,5579), exibiu melhoria em 2010 (0,6360), mas, em 2015, o valor voltou a cair, correspondendo a 0,5944. Esse foi o pior resultado de toda a microrregião ao final do estudo. Já o melhor resultado em 2015 foi observado em São João del-Rei $(0,7598)$, provavelmente por este ser a cidade-polo da região. 
Em termos percentuais, o município que apresentou maior aumento no Índice Firjan entre 2005 e 2015 foi Ritápolis. Em 2005 seu IFDM era de 0,5112 e em 2015 esse valor passou para 0,7051. Também considerando a diferença percentual, Dores de Campos foi o que menos cresceu (2,58\%), indo de 0,7363 para 0,7553. Esse baixo crescimento, porém, não significa que o município está em uma situação ruim, muito pelo contrário. Ele começou o período de análise com o melhor resultado da microrregião - 0,7363 e terminou em segundo lugar - 0,7553 -, atrás apenas de São João del-Rei. O bom resultado se manteve por todo o período de pesquisa.

Prados foi o único município, também considerando o valor de 2005 e 2015, que apresentou decréscimo do Índice Firjan (-0,92\%). Apesar de a variação ser uma pequena, é uma situação preocupante, uma vez que o movimento não foi observado em nenhum outro município da microrregião.

\subsection{Análise dos Indicadores do Índice Firjan}

Além do desenvolvimento econômico, a garantia dos direitos básicos figura entre os principais objetivos das nações, de forma que o Estado busca, constitucionalmente, assegurá-los por meio de políticas públicas. Tanto a implementação quanto a manutenção partem de um processo de tomada de decisões que envolvem órgãos públicos e diferentes organismos e agentes da sociedade relacionados à política implementada (HÖFLING, p. 31, 2001).

É importante analisar os gastos públicos, pois estes têm impactos diferenciados conforme o nível de governo que se esteja analisando. Como é no nível municipal que se dá a efetivação dos gastos públicos para atender às necessidades da população, a eficiência alocativa desses gastos é condição necessária para que os esforços do setor público estadual e federal possam alcançar os objetivos esperados (MARINHO; NETO, 1999, p. 140).

Para chegar ao valor dos gastos públicos per capita em saúde e educação, os valores brutos anuais desses dois setores foram divididos pela população estimada anual. Após isso, para os avaliar temporalmente os resultados, os valores foram inflacionados para o ano de 2015, pelo INPC (Tabela 1).

Tabela 1 - Evolução dos gastos per capita na educação na microrregião de São João del-Rei

Gasto per capita com educação Participação do Gasto com educação no PIB

(\$)

$(\%)$

\begin{tabular}{lcccccc}
\hline & 2005 & 2010 & 2015 & 2005 & 2010 & 2015 \\
\cline { 2 - 7 } $\begin{array}{l}\text { Conceição da Barra } \\
\text { Minas }\end{array}$ & & & & & & \\
Coronel Xavier Chaves & 314,61 & 450,44 & 587,86 & 4,03 & 4,53 & 6,51 \\
Dores de Campos & 226,02 & 362,14 & 653,35 & 2,24 & 2,70 & 4,77 \\
Lagoa Dourada & 317,92 & 487,68 & 774,79 & 4,44 & 5,01 & 6,04 \\
Madre de Deus de Minas & 289,91 & 376,94 & 500,99 & 2,94 & 3,29 & 2,32 \\
Nazareno & 285,37 & 469,39 & 479,68 & 2,11 & 3,25 & 1,85 \\
Piedade do Rio Grande & 295,12 & 446,25 & 592,41 & 1,23 & 1,63 & 4,18 \\
Prados & 248,71 & 348,61 & 485,27 & 3,63 & 4,20 & 3,38 \\
Resende Costa & 247,60 & 362,26 & 448,94 & 3,93 & 4,97 & 4,28 \\
Ritápolis & 312,70 & 379,15 & 493,16 & 4,87 & 5,45 & 4,53
\end{tabular}

Revista Desenvolvimento Socioeconômico em debate v.7 n.2 (2021) 


\begin{tabular}{lcccccc} 
Santa Cruz de Minas & 171,98 & 205,44 & 291,79 & 4,04 & 3,31 & 3,05 \\
Santana do Garambéu & 579,32 & 921,84 & 927,83 & 10,57 & 12,69 & 8,99 \\
São João del-Rei & 165,16 & 226,46 & 320,83 & 1,55 & 1,66 & 1,72 \\
São Tiago & 184,59 & 284,27 & 351,74 & 2,47 & 3,65 & 2,86 \\
Tiradentes & 358,12 & 442,87 & 645,85 & 3,16 & 3,01 & 3,58 \\
\hline
\end{tabular}

Fonte: Elaboração própria a partir de dados do Tesouro Nacional (2019).

De todos os municípios da microrregião, aquele que mais investiu em educação, levando em conta sua participação no PIB, foi Santana do Garambéu. Logo em seguida veio Lagoa Dourada e Conceição da Barra de Minas com o gasto com educação representando no PIB, em 2015, 6,61\% e 6,51\%, respectivamente. Santa Cruz de Minas, em 2015, apresentou o menor investimento per capita em educação da microrregião. Além disso, houve diminuição ao longo dos anos, considerando o valor em relação ao PIB.

São João del-Rei, o maior município da região, também apresentou baixo investimento na área de educação em 2015. Porém, apesar do resultado, ele veio melhorando ao longo dos anos. Em relação aos municípios que mostraram diminuição da participação do gasto em educação no PIB, os que mais se destacaram foram Madre de Deus de Minas, Nazareno e Prados. Todos tiveram resultado baixo no primeiro ano, aumentaram no segundo e voltaram a cair em 2015.

Segundo o último relatório da Education at a Glance, publicado pelo INEP (2018), o gasto público total em educação no Brasil, em 2015, correspondia a 5\% do PIB brasileiro, que é a exata porcentagem da média de investimento dos países que fazem parte da OCDE. Fazendo uma comparação com os municípios da microrregião, os únicos que ficaram acima do valor apresentado pelo Brasil foram Conceição da Barra de Minas, Lagoa Dourada e Santana do Garambéu.

Contudo, apesar de estes locais gastarem uma porcentagem relativamente alta do PIB (maior até do que muitos países desenvolvidos), isso não significa que o suficiente está sendo investido. $\mathrm{O}$ valor que pode ser ideal para uma cidade desenvolvida pode ser insuficiente para municípios periféricos, pois estes têm suas próprias especificidades (escolas rurais, ribeirinhas ou outras).

Assim como aconteceu no caso educação, os investimentos na saúde, num primeiro momento, não se mostraram diretamente relacionados com o desenvolvimento social dos municípios e nem com a excelência do sistema público de saúde (Tabela 2).

Tabela 2 - Investimento na área da saúde na microrregião de São João del-Rei

\begin{tabular}{|c|c|c|c|c|c|c|}
\hline & \multicolumn{3}{|c|}{ Gasto per capita com saúde } & \multicolumn{3}{|c|}{$\begin{array}{c}\text { Porcentagem do PIB } \\
\text { empenhado em saúde }(\%)\end{array}$} \\
\hline & 2005 & 2010 & 2015 & 2005 & 2010 & 2015 \\
\hline Conceição da Barra de Minas & 337,98 & 482,54 & 669,28 & 5,07 & 7,16 & 6,78 \\
\hline Coronel Xavier Chaves & 367,32 & 446,95 & 754,24 & 4,71 & 4,57 & 6,12 \\
\hline Dores de Campos & 240,23 & 306,05 & 478,04 & 2,38 & 2,28 & 2,20 \\
\hline Lagoa Dourada & 200,54 & 388,81 & 402,51 & 2,80 & 4,66 & 3,43 \\
\hline Madre de Deus de Minas & 361,55 & 492,58 & 781,95 & 3,66 & 4,30 & 3,62 \\
\hline Nazareno & 227,73 & 338,22 & 696,29 & 1,68 & 2,34 & 2,69 \\
\hline
\end{tabular}




\begin{tabular}{|c|c|c|c|c|c|c|}
\hline Piedade do Rio Grande & 352,91 & 596,19 & 803,10 & 1,47 & 2,17 & 5,67 \\
\hline Prados & 196,52 & 338,12 & 416,68 & 2,87 & 4,07 & 2,90 \\
\hline Resende Costa & 153,27 & 247,55 & 381,99 & 2,43 & 3,39 & 3,64 \\
\hline Ritápolis & 249,98 & 359,30 & 560,78 & 3,90 & 5,16 & 5,15 \\
\hline Santa Cruz de Minas & 178,05 & 256,31 & 382,80 & 4,18 & 4,13 & 4,00 \\
\hline Santana do Garambéu & 575,19 & 755,71 & 1294,26 & 10,49 & 10,40 & 12,53 \\
\hline São João del-Rei & 306,70 & 465,51 & 731,41 & 2,88 & 3,40 & 3,93 \\
\hline São Tiago & 192,77 & 326,94 & 435,87 & 2,58 & 4,19 & 3,54 \\
\hline Tiradentes & 392,28 & 448,19 & 549,07 & 3,46 & 3,04 & 3,04 \\
\hline
\end{tabular}

Fonte: Elaboração própria a partir de dados do Tesouro Nacional (2019).

O município que mais recebeu investimentos em saúde, considerando a participação desse gasto no PIB, foi Santana do Garambéu - 12,53\% em 2015. Em seguida aparece Conceição da Barra de Minas e Coronel Xavier Chaves, apresentando a participação no gasto com saúde no PIB de 6,78\% e 6,12\%, respectivamente.

No Brasil, os gastos públicos com saúde significaram 3,8\% do PIB em 2015, segundo dados publicados pela secretaria do Tesouro Nacional no relatório Aspectos Fiscais da Saúde no Brasil (2018, p. 2). Dos municípios estudados, os que apresentaram a participação no PIB do gasto com saúde inferior ao valor registrado pelo Brasil foram Dores de Campos, Lagoa Dourada, Madre de Deus de Minas, Nazareno, Prados, Resende Costa, São Tiago e Tiradentes.

Segundo Travassos e Viacava (2007), a predominância de pessoas de baixo poder aquisitivo na população rural e a ausência de vínculo empregatício fazem com que o SUS seja mais utilizado que o serviço privado de saúde. A maior dificuldade para acessar os serviços nas áreas rurais, segundo eles, estaria associada à menor disponibilidade de serviços de acompanhamento de internações e acidentes, as quais se encontram, usualmente, a distâncias maiores, necessitando que o indivíduo se desloque.

Dada a ligação do PIB per capita municipal ao componente Renda do Índice Firjan, é de extrema importância observar a trajetória dessa dimensão ao longo dos anos para a microrregião de São João del-Rei. Selecionamos duas teorias que norteiam esse comportamento: a Hipótese da Convergência, de Solow (1956), e a Teoria da Causação Circular e Acumulativa, de Myrdal (1957). Os dois autores serão revistos com o intuito de apontar qual teoria mais se assemelha com o comportamento de PIB per capita dos municípios entre 2000 e 2015.

Em seu estudo inicial, Myrdal (1957) usou como referência os países desenvolvidos da Europa Ocidental e da África e os países subdesenvolvidos da América Latina. O autor procurou entender as distorções econômicas entre os países desenvolvidos e subdesenvolvidos, utilizando como instrumento os níveis de renda (alto para os desenvolvidos e baixos para subdesenvolvidos), e volume de investimento. Ele chegou à conclusão que, em geral, os países ricos se encontram em processo de desenvolvimento contínuo, enquanto nos países pobres o progresso é mais lento. Com isso, as desigualdades econômicas entre os países desenvolvidos e subdesenvolvidos tendem a aumentar (SILVA; MARION FILHO; CORONEL, 2006).

Para Myrdal (1957), o papel do Estado é importante no sentido de tentar diminuir as desigualdades regionais. A atuação deste, através de políticas econômicas, deve neutralizar os efeitos regressivos e promover os propulsores nas regiões periféricas, promovendo o desenvolvimento.

Já no modelo de Sollow (1956), a propriedade de convergência surge da suposição de que os fatores de produção teriam retornos decrescentes. De acordo com a teoria, países com dotação 
maior de capital tenderiam a ter retornos menores para seus fatores do que os países com menor dotação. Assim, haveria tendência de os países pobres crescerem mais rapidamente e diminuírem a diferença no nível de renda em relação aos países mais ricos. A utilização deste modelo permite fazer uma análise da distribuição de renda entre os municípios de uma região, informando-nos sobre a dinâmica dos locais relativamente mais pobres em relação aos mais ricos. (AMORIM; SCALCO; BRAGA, 2008, p. 360).

Para definir a tendência do PIB per capita dos municípios, é apresentada, a seguir, a variação percentual do PIB municipal. É importante elucidar que os valores foram todos trazidos para a mesma base (2000) pelo Índice Nacional de Preços ao Consumidor (INPC) (PORTAL BRASIL, 2019) (Tabela 3).

Tabela 3 - Variação do PIB per capita na microrregião de São João del-Rei (\%)

\begin{tabular}{|c|c|c|c|}
\hline & $2000-2005$ & $2005-2010$ & $2010-2015$ \\
\hline Conceição da Barra de Minas & 15,96 & 0,93 & 17,41 \\
\hline Coronel Xavier Chaves & 4,16 & 25,36 & 1,09 \\
\hline Dores de Campos & 28,61 & 32,78 & 29,72 \\
\hline Lagoa Dourada & 22,06 & 16,55 & 12,58 \\
\hline Madre de Deus de Minas & 69,79 & 16,13 & 51,19 \\
\hline Nazareno & 36,33 & 6,65 & 43,67 \\
\hline Piedade do Rio Grande & 81,66 & 14,06 & $-58,60$ \\
\hline Prados & 24,69 & 21,21 & 38,67 \\
\hline Resende Costa & 16,26 & 15,66 & 15,26 \\
\hline Ritápolis & 12,98 & 8,51 & 25,38 \\
\hline Santa Cruz de Minas & 11,24 & 45,58 & 23,75 \\
\hline Santana do Garambéu & 9,29 & 32,63 & 13,91 \\
\hline São João del-Rei & 10,61 & 28,30 & 9,21 \\
\hline São Tiago & 7,80 & 4,44 & 26,40 \\
\hline Tiradentes & 47,02 & 29,78 & $-1,80$ \\
\hline Microrregião & 19,11 & 23,17 & 14,25 \\
\hline
\end{tabular}

Fonte: Elaboração própria a partir de dados do IBGE (2016).

Todos os municípios apresentaram crescimento ao longo dos anos, com exceção de Tiradentes e Piedade do Rio Grande, que de 2010 para 2015, diminuíram o PIB em 1,8\% e $58,60 \%$, respectivamente. Apesar da expressiva variação percentual negativa de Piedade do Rio Grande, o município não chegou ao final do período de análise com uma renda tão baixa, apenas aproximou seu resultado ao patamar microrregional. O seu PIB per capita foi o que apresentou comportamento mais anormal entre todos: desde o ano 2000, a renda média por habitante nesse município foi se descolando dos valores registrados pelo resto da região; depois do seu pico em 2009 , contudo, quando alcançou $\mathrm{R} \$ 35.500,68$, a renda passou a decair, convergindo, nos últimos anos de estudo, para os resultados alcançados pelos outros municípios (IBGE, 2016). 
Os maiores crescimentos, em termos percentuais, no PIB per capita, foram observados em Dores de Campos, Madre de Deus de Minas, Nazareno e Prados. Em 2015, esses municípios ficaram entre os que apresentaram as maiores rendas da microrregião.

Segundo um estudo de Marinho e Neto (p. 156, 1999), somente os municípios menos desenvolvidos tem seu índice de desenvolvimento humano influenciado positivamente pelo PIB per capita. Como os municípios mais desenvolvidos e de desenvolvimento intermediário são, em geral, mais intensivos em capital, acaba-se gerando uma maior concentração de renda. Na microrregião de São João del-Rei, há predominância de municípios de pequeno porte, com população inferior a 10 mil habitantes. Dessa forma, infere-se que, apesar de a renda per capita desses municípios terem sido menores do que o valor registrado no Brasil, há menos concentração de renda.

Em síntese, o mais elevado PIB per capita foi observado em Nazareno - que possui a mineração como principal atividade - e o menor em Santa Cruz de Minas - onde seu principal atrativo é o artesanato. Observa-se uma tendência de perpetuação da pobreza nos municípios com menor renda e da riqueza nas regiões mais prósperas. O mais preocupante é que a diferença entre as taxas de crescimento do PIB per capita dos municípios mais ricos e o dos municípios mais pobres se tornou maior, indicando a existência de uma condição da causação circular e acumulativa de Myrdal.

Contudo, quando analisamos o Índice Firjan por indicador - Educação, Saúde e Emprego e Renda -, é possível fazer análises mais aprofundadas da origem dos altos ou baixos valores para o IFDMs anuais. Dores de campos foi o único município que, desde o começo do estudo, apresentou IFDM acima de 0,7000. O resultado se deu, em grande medida, pelo indicador "Saúde" do índice, que atingiu 0,8094 em 2015. Já o menor valor do indicador "Saúde", em 2015, foi observado para o município de São Tiago - 0,5628.

O indicador de "Educação" de São João del-Rei foi o maior da microrregião, e isso pode estar relacionado às várias instituições de ensino localizadas na cidade. Além das escolas de Ensino Básico (Educação Infantil, Ensino Fundamental e Ensino Médio), o município também conta com instituições de nível superior. A Universidade Federal de São João del-Rei (UFSJ) é considerada a principal do município, mas ainda há o Centro Universitário Presidente Tancredo de Almeida Neves (UNIPTAN), o Campus São João del-Rei do Instituto Federal do Sudeste de Minas (IF-Sudeste), e os polos de educação à distância da Universidade Aberta do Brasil, do Centro Universitário Internacional (UNINTER), da Universidade Paulista (UNIP), da Universidade do Sul de Santa Catarina (UNISUL) e da Universidade Católica de Brasília (UCB) (DESTAQUE MINAS, 2019).

O município também conta com creches, Ensino Técnico e Ensino Integral. As escolas que implementaram o Ensino Integral oferecem uma matriz curricular articulada entre as áreas de conhecimento e os campos integradores. Dessa forma, além das matérias regulares da base comum, os alunos têm aulas de projeto de vida, cultura e saberes em arte, educação para cidadania, laboratório de matemática, ciências e tecnologia, entre outras (SRE/SJDR, 2019).

São João del-Rei, além de apresentar o melhor índice para educação, surpreende ao ter, também, o maior valor para o indicador de emprego e renda - 0,6433. Esse resultado pode ter sido alcançado pelo bom desempenho do comércio local, uma vez que seu amplo centro de compras movimenta a economia e gera empregos - valores que são incorporados no indicador Emprego e Renda do Índice Firjan. Além disso, desde 2002, o município tem tido um alto crescimento da especulação imobiliária, incentivado, em parte, pela ampliação da Universidade Federal de São João del-Rei (UFSJ), a qual contribuiu significativamente para a atração de pessoas na cidade (COTA; DÓRIO, 2014, p. 74).

Dos municípios estudados, 6 chegaram a 2015 com índice de desenvolvimento superior a 0,7000. Isso é bem próximo ao grau de desenvolvimento alcançado por municípios mais 
prósperos, como é o caso de Belo Horizonte, por exemplo. Para se ter uma ideia, Belo Horizonte ocupa a $3^{\circ}$ posição no ranking do IFDM consolidado estadual de 2015. Já em relação à microrregião de estudo, o primeiro município a aparecer na lista é São João del-Rei, em $63^{\circ}$ lugar estadual. Dores de Campos e Madre de Deus de Minas surgem logo em seguida, nas posições 69 e 138, respectivamente. Dos municípios estudados, o último a surgir na lista foi Santa Cruz de Minas em $728^{\circ}$ lugar do total de 853 municípios mineiros.

Dentre os municípios que apresentaram aumento no Índice Firjan ao longo dos anos, Ritápolis merece destaque. Entre 2005 e 2015, este teve um crescimento de 37,97\%, com uma trajetória ascendente que só foi interrompida em 2008. Evidentemente não foi só ele que apresentou essa tendência, mas toda a microrregião. O gráfico 2 expressa essa evolução, fazendo uma comparação entre o IFDM da microrregião com os seus componentes de Educação, Saúde, Emprego e Renda.

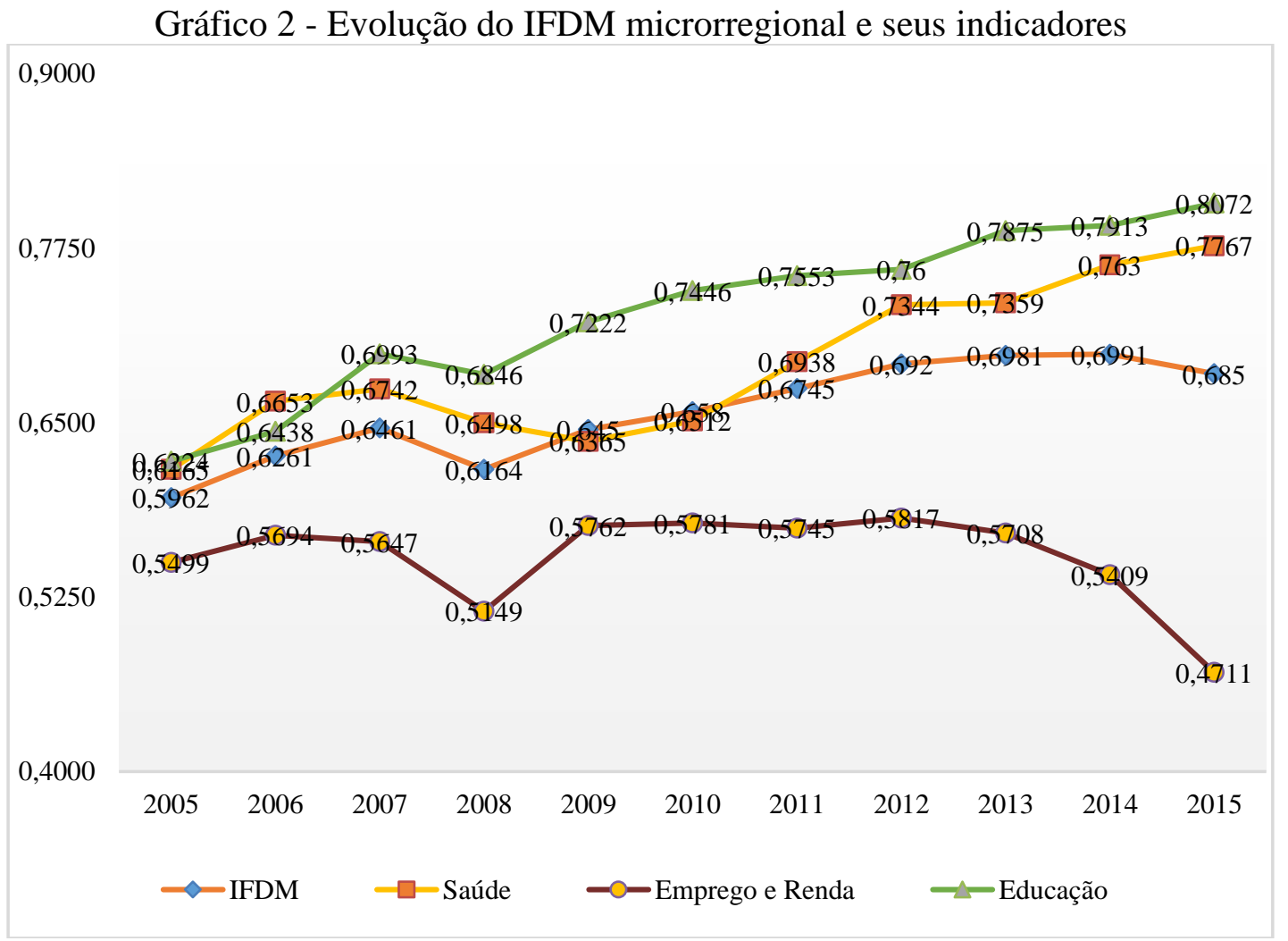

Fonte: Elaboração própria a partir de dados da Firjan (2019).

Assim como é feito o cálculo do IFDM Brasil (Firjan, 2018b), o IFDM da microrregião de São João del-Rei foi elaborado a partir da média dos índices de todos os municípios que a ela pertencem. Como praticamente todos os municípios apresentaram trajetória ascendente, a média microrregional também alcançou bons resultados. O principal momento de queda foi em 2008, quando o indicador Emprego e Renda arrastou o IFDM para baixo, possivelmente em resposta à crise mundial.

A dimensão Emprego e Renda do IFDM avalia, basicamente, a capacidade de geração de emprego formal, o nível de absorção da mão de obra local e a geração e distribuição de renda no mercado de trabalho formal do município. Então, como uma crise econômica afeta principalmente a dinâmica trabalhista, a partir do aumento do desemprego, da informalidade e da rotatividade da mão-de-obra nacional, por exemplo, a dimensão Emprego e Renda do IFDM foi a mais impactada. 
O desempenho da economia brasileira no biênio 2008-2009 e algumas políticas econômicas adotadas pelo governo federal contrabalancearam os efeitos da crise. Os resultados encontrados por Ferraz (2013) sugerem que a política econômica praticada foi relativamente bem-sucedida no sentido de proporcionar uma rápida reação do nível de atividade e impedindo a queda do nível de emprego. Então, em 2009, acompanhando o movimento da economia brasileira, o IFDM médio da microrregião retomou sua trajetória de crescimento.

No geral, a demanda brasileira foi fortalecida pelo efeito redistributivo das políticas de expansão do salário mínimo e de transferência de renda para a população mais pobre. Como a propensão a poupar desta camada da população é baixa, repasses a esse grupo possuem um grande poder de estímulo à demanda doméstica e, consequentemente, à produção e ao emprego. Dessa forma, a política fiscal do governo teve efeitos importantes: contínua redução do desemprego, rápida recuperação da taxa de crescimento (em 2010 PIB cresceu aproximadamente $7,5 \%$ em termos reais) e a sustentação de certas atividades econômicas (aumento na venda de automóveis, por exemplo), indicando que a política fiscal adotada pelo governo federal, naquele período, foi um sucesso (FERRAZ, 2013, p. 98).

No período 2014 - 2015, provavelmente impactado pela forte recessão econômica que atingiu a economia brasileira, o IFDM Emprego e Renda da microrregião de São João del-Rei voltou a cair. A crise econômica teve início em meados de 2014 e gerou recuo no produto interno bruto (PIB) por dois anos consecutivos - cerca de 3,8\% em 2015 e 3,6\% em 2016. A crise foi acompanhada e intensificada por uma crise política, que resultou em protestos contra o governo Dilma por todo o país. A presidente, que tinha sido reeleita para seu segundo mandato, foi definitivamente afastada do cargo em agosto de 2016, por meio de um processo de impeachment (ÉPOCA, 2016).

\subsection{O progresso do desenvolvimento humano}

Segundo o PNUD (2003), na publicação do Informe sobre Desarrollo Humano, o desenvolvimento humano estende o potencial de crescimento econômico, pois favorece a formação de capital humano. Uma melhor nutrição faz com que a força de trabalho tenha mais energia, maior resistência a doenças e, ainda por cima, maior produtividade. Uma população com melhor saúde representa continuidade no trabalho, maior disponibilidade de horas-homem e uma extensão na vida profissional das pessoas. Melhores níveis educacionais facilitam o treinamento de habilidades para o trabalho, o uso de novas tecnologias e maiores oportunidades de emprego.

A relação entre produtividade e desenvolvimento humano não é direta, já que o mesmo nível de renda pode se traduzir em diferentes potenciais para o desenvolvimento humano e viceversa. E, assim como existe um círculo virtuoso entre crescimento e desenvolvimento humano, também pode haver um círculo vicioso devido à ausência de qualquer um deles. Para Myrdal (1968), uma situação de pobreza ou bonança se reforçam cumulativamente e, para que se rompa qualquer círculo vicioso, é crucial identificar as regiões que se encontram nesse processo.

Com isso, inspirada na metodologia utilizada pelo PNUD (2003) no Informe sobre Desarrollo Humano, os municípios da microrregião foram identificados de acordo com o seu perfil de desenvolvimento, seguindo a classificação abaixo:

- Círculo Vicioso: PIB per capita, educação e saúde apresentando piores resultados que a média microrregional;

- Tendência ao Crescimento: PIB per capita acima da média microrregional, mas não os indicadores sociais (educação e/ou saúde).

- Tendência Desenvolvimento: PIB per capita abaixo da média nacional, mas o índice de educação e/ou saúde com valores acima do valor médio. 
- Círculo Virtuoso: PIB per capita, educação e saúde apresentando melhores resultados que a média microrregional.

Para facilitar a verificação do tipo de desenvolvimento observado nos municípios, uma tabela foi elaborada (Tabela 4), seguindo a seguinte legenda:

1 - Círculo Vicioso

2 - Tendência ao Crescimento

3 - Tendência ao Desenvolvimento

4 - Círculo Virtuoso

Tabela 4 - Tipo de desenvolvimento dos municípios da microrregião de São João del-Rei, de acordo com a metodologia do Informe sobre Desarrollo

\begin{tabular}{lrrr}
\hline Ano & 2005 & 2010 & 2015 \\
\hline Conceição da Barra de Minas & 1 & 3 & 3 \\
Coronel Xavier Chaves & 3 & 1 & 3 \\
Dores de Campos & 4 & 4 & 4 \\
Lagoa Dourada & 1 & 3 & 3 \\
Madre de Deus de Minas & 4 & 3 & 2 \\
Nazareno & 4 & 4 & 4 \\
Piedade do Rio Grande & 4 & 2 & 3 \\
Prados & 3 & 3 & 1 \\
Resende Costa & 3 & 3 & 3 \\
Ritápolis & 1 & 3 & 3 \\
Santa Cruz de Minas & 1 & 3 & 1 \\
Santana do Garambéu & 3 & 3 & 3 \\
São João del-Rei & 2 & 2 & 4 \\
São Tiago & 3 & 1 & 3 \\
Tiradentes & 2 & 2 & 2 \\
\hline
\end{tabular}

Fonte: Elaboração própria a partir de dados da Firjan (2019) e do IBGE (2016).

Dos municípios acima, Dores de Campos e Nazareno se destacam por terem apresentado Círculo Virtuoso desde o começo do ano de estudo. Para entender quais são as determinantes dessa prosperidade, foram utilizados os dados do Atlas do Desenvolvimento Humano no Brasil (2019a; 2019b), que se baseiam nas informações coletadas pelo Censo Demográfico de 2010.

De acordo com a publicação, o município de Dores de Campos possui 90,95\% da população vivendo na área urbana e 9,05\% de população na rural, com 97,42\% dos habitantes tendo em seus domicílios banheiro e água encanada. A mortalidade infantil (mortalidade de crianças com menos de um ano de idade) era, em 2010, de 16,3 óbitos por mil nascidos vivos e a esperança de vida ao nascer era de 74,4. Em relação à educação, a taxa de escolarização para as pessoas entre 6 e 14 anos de idade era de 99,2\%, e dos jovens adultos (18 a 24 anos) que estavam cursando o ensino superior, 12,79\% (ATLAS BRASIL, 2019a).

Já Nazareno, a população urbana ocupa $76,01 \%$ do território, enquanto a rural $23,99 \%$, tendo $94,17 \%$ dos habitantes vivendo em domicílios com água encanada 94,17\%. Em 2010, a 
mortalidade infantil no município era de 15,6 óbitos por mil nascidos vivos, enquanto a esperança de vida ao nascer era de 74,82 anos. No município, 5,70\% dos jovens adultos estavam cursando o ensino superior em 2010. A proporção de crianças de 5 a 6 anos na escola é de $92,27 \%$, em 2010. No mesmo ano, a proporção de crianças de 11 a 13 anos frequentando os anos finais do ensino fundamental era de 85,26\%; a proporção de jovens de 15 a 17 anos com ensino fundamental completo, 62,47\%; e a proporção de jovens de 18 a 20 anos com ensino médio completo era de $41,01 \%$ (ATLAS BRASIL, 2019b).

Nos dois municípios, a esperança de vida ao nascer foi maior que a registrada no Brasil, que, em 2010, era de 73,9 anos. Os dois também cumpriram uma das metas dos Objetivos de Desenvolvimento do Milênio das Nações Unidas, segundo a qual a mortalidade infantil deveria estar abaixo de 17,9 óbitos por mil nascidos até o ano de 2015 (NAÇÕES UNIDAS, 2015). Além disso, mesmo sendo municípios pequenos, Dores de Campos e Nazareno apresentam bons indicadores habitação, uma vez que a imensa maioria dos seus domicílios possuem água encanada, energia elétrica e coleta de lixo.

Os municípios que apresentaram o perfil do tipo Desenvolvimento, de acordo com o método do Informe sobre Desarrollo Humano, nos três anos de estudo, foram Resende Costa e Santana do Garambéu. Apesar de estes terem apresentado PIB per capita abaixo do valor da microrregião, a sua dinâmica interna, como acreditam muitos teóricos do desenvolvimento, tende a propiciar um bem-estar cada vez maior da população.

Já o município de Tiradentes foi o único da microrregião que apresentou, nos três anos, perfil de crescimento econômico. Isso pode estar ligado à enorme circulação monetária advinda da atividade turística, uma vez que esta contribui para o aumento de empregos diretos e indiretos.

Apesar de nenhum município ter demonstrado Círculo Vicioso nos três anos seguidos, Madre de Deus de Minas e Prados foram decaindo o grau de desenvolvimento ao longo do tempo. O primeiro município, no ano 2000, estava em um Círculo Virtuoso, partiu para uma Tendência ao Desenvolvimento e fechou o ano de 2015 em fase de Crescimento. Já Prados, em 2005 e 2010, estava em fase de Desenvolvimento, porém, em 2015, caiu para um Círculo Vicioso. Por outro lado, os municípios que melhoram sua situação entre 2000 e 2015 foram Conceição da Barra de Minas, Lagoa Dourada e Ritápolis; eles estavam em um ciclo vicioso em 2000 e passaram para "Tendência ao Desenvolvimento" em 2010 e 2015.

Percebe-se que, no geral, os municípios que estavam em um ciclo vicioso ou com indicadores sociais defasados tiveram uma dificuldade para melhorar sua situação, devido, segundo afirma Myrdal (1957) à retroalimentação da pobreza (causação circular e cumulativa). É importante, dessa forma, que os indivíduos de uma sociedade tenham igualdade de oportunidades, pois esse é um dos principais caminhos para se alcançar melhorias nos indicadores de capital humano, dado que quanto mais se entende a interrelação dos fatores econômicos e sociais, maiores as chances de se alcançar bons resultados em termos de políticas públicas (RAIHER; FERRERA DE LIMA, 2014).

Em suma, de acordo com o tipo de desenvolvimento estabelecido pelo Informe sobre Desarrollo, tanto os indicadores sociais quanto os econômicos de Dores de Campos e Nazareno apresentaram ótimos resultados para os três anos (Círculo Virtuoso). Resende Costa e Santana do Garambéu, em todo o período, apresentaram perfil de Desenvolvimento; já Tiradentes, Crescimento. Madre de Deus de Minas e Prados foram piorando a situação ao longo do estudo, enquanto Conceição da Barra de Minas, Lagoa Dourada e Ritápolis melhoraram. Observa-se que os municípios que estavam em Círculo Vicioso ou com indicadores sociais defasados tiveram dificuldades de melhorar sua situação, sugerindo uma causação circular cumulativa. 


\section{CONCLUSÕES}

A partir do presente estudo, observa-se que ocorreu melhoria nos índices de desenvolvimento econômico na maioria dos municípios da microrregião. $\mathrm{O}$ aumento de renda, em boa parte destes, não causou a expansão da desigualdade de renda, possivelmente em resposta aos programas do governo de transferência direta de renda às famílias pobres. O lado negativo, porém, é que o PIB per capita microrregional cresceu em ritmo mais lento que o do Brasil, principalmente a partir de 2008, quando ocorreu a crise mundial.

Em termos econômicos, Nazareno merece destaque, já que, ao final do estudo, atingiu o maior PIB per capita da microrregião, apresentando baixa concentração de renda e IFDM com desenvolvimento moderado. Seus gastos públicos per capita com saúde e educação ficaram bem abaixo da média microrregional e, segundo a metodologia do Informe sobre Desarrollo, o município apresentou Círculo Virtuoso em todos os anos de estudo.

O melhor resultado para o IFDM, em 2015, foi visto em São João del-Rei $(0,7598)$. A cidade polo da microrregião apresentou alto PIB per capita, altos gastos com saúde e baixos dispêndios em educação. Em 2005 e 2010, o município apresentava perfil de Tendência ao Crescimento, de acordo com a metodologia do informe sobre Desarrollo; em 2015, contudo, ele passou a apresentar um Círculo Virtuoso - variáveis econômicas e sociais acima da média da microrregião.

Dores de Campos também foi um município que se saiu muito bem; mesmo com baixos gastos públicos, este conseguiu alcançar resultados favoráveis para o IFDM e o PIB per capita. Ele se distingue dos outros por ter apresentado IFDM acima de 0,7000 e Círculo Virtuoso em 2005, 2010 e 2015.

Já o mais baixo PIB per capita foi observado em Santa Cruz de Minas, onde a principal atividade econômica - artesanato - agrega pouco ao PIB. No ano de 2015, o município foi o que menos gastou com educação per capita e apresentou o segundo menor gasto com saúde da microrregião. Terminou o estudo como o pior IFDM entre os municípios $(0,5944)$ e, de acordo com a metodologia inspirada na do Informe sobre Desarrollo Humano, manisfestou perfil de Círculo Vicioso.

Observa-se que, no geral, apesar de a crise mundial de 2008 ter afetado fortemente o indicador Emprego e Renda de toda a microrregião, as políticas adotadas pelo governo federal rapidamente contrabalancearam seus efeitos. Em relação ao desenvolvimento dos municípios, houve uma tendência de perpetuação da pobreza nos municípios com menor renda e da riqueza nas regiões mais prósperas.

A diferença entre o PIB per capita dos municípios mais ricos e o dos municípios mais pobres se tornou maior, sugerindo, então, que há uma espécie de Causação Circular Cumulativa agindo sobre eles. Os municípios que estavam em Círculo Vicioso ou com indicadores sociais defasados, com é o caso de Prados, Santa Cruz de Minas e Tiradentes, tiveram dificuldades de mudar sua situação; enquanto os que se mostraram prósperos desde o começo do estudo, com indicadores sociais e econômicos acima da média microrregional, tenderam a se manter em boa posição (Dores de Campos e Nazareno).

Finalmente, vale destacar que existem fatores não incluídos na análise que impactam os resultados da desigualdade. Portanto, sugere-se que pesquisas futuras estudem as questões relativas aos condicionantes locais, como, por exemplo, a infraestrutura social dos municípios.

\section{REFERÊNCIAS}

AMORIM, Airton Lopes; SCALCO, Paulo Roberto; BRAGA, Marcelo José. Crescimento econômico e convergência de renda nos estados brasileiros: Uma análise a partir dos grandes setores da economia. Revista Econômica do Nordeste, v. 39, n. 3, p. 359-370, 2008. 
ATLAS BRASIL. Dores de Campos, c2019a. Disponível em:

<http://www.atlasbrasil.org.br/2013/pt/perfil_m/dores-de-campos_mg>. Acesso em: 30 de out. de 2019.

ATLAS BRASIL. Nazareno, MG, c2019b. Disponível em:

http://www.atlasbrasil.org.br/2013/pt/perfil_m/nazareno_mg. Acesso em: 30 de out. de 2019.

BRESSER-PEREIRA, Luiz Carlos. Crescimento e desenvolvimento econômico. Notas para uso em curso de desenvolvimento econômico na Escola de Economia de São Paulo da Fundação Getúlio Vargas. Versão de jun. 2008. Disponível em:

http://www.bresserpereira.org.br/Papers/2007/07.22.CrescimentoDesenvolvimento.Junho19.2008.pdf. Acesso em: 10 set. 2019.

COTA, Daniela Abrita; DIÓRIO, Ana Carolina Dias. Cidade intermediária e rede urbana: o caso de São João del-Rei (MG). Cadernos de Arquitetura e Urbanismo, v. 21, n. 28, p. 66-85, 2014.

DESTAQUE MINAS. São João del-Rei. c2019. Disponível em:

http://destaqueminas.com.br/portal/cidades/sao-joao-del-dey-mg/. Acesso em: 20 de out. de 2019.

ÉPOCA. A ascensão e a decadência de Dilma - a descida, 18 abr. 2016. Disponível em: https://epoca.globo.com/tempo/noticia/2016/04/ascensao-e-decadencia-de-dilma-descida.html. Acesso em: 27 ago. 2019.

ERVILHA, Gabriel Teixeira; ALVES, Frederick Fagundes; GOMES, Adriano Provezano. Desenvolvimento municipal e eficiência dos gastos públicos na Bahia: uma análise do IFDM a partir da metodologia DEA. Encontro de Economia Baiana, v. 9, p. 106-124, 2013.

FERRAZ, Fernando Cardoso. Crise financeira global: impactos na economia brasileira, política econômica e resultados. Rio de Janeiro: UFRJ, 2013.

FERREIRA JÚNIOR, S.; BAPTISTA, A. J. M. S.; LIMA, J. E. A modernização agropecuária nas microrregiões do Estado de Minas Gerais. Revista de Economia e Sociologia Rural, v.42, n.1, 2004.

FIRJAN. Índice Firjan de Desenvolvimento Municipal (IFDM) - Consulta ao Índice, c2019. Disponível em: <https://www.firjan.com.br/ifdm/consulta-ao-indice/>. Acesso em 25 set. 2019.

FIRJAN. Metodologia do IFDM, 2018a. Disponível em:

https://www.firjan.com.br/data/files/46/21/E2/BD/DF834610C4FC8246F8A809C2/Metodologia\%20IFD M\%20-\%20Final.pdf. Acesso em: 04 de abr. de 2019.

FIRJAN. Publicções Firjan - Pesquisas e Estudos socioeconômicos, 2018b. Disponível em: https://www.firjan.com.br/data/files/67/A0/18/D6/CF834610C4FC8246F8A809C2/IFDM_2018.pdf. Acesso em 17 de out. de 2019.

HÖFLING, Eloisa de et al. Estado e políticas (públicas) sociais. Cadernos Cedes, 2001. Disponível em: http://www.scielo.br/pdf/ccedes/v21n55/5539. Acesso em 13 jun. 2019

IBGE, Instituto Brasileiro de Geografia e Estatística. Áreas dos Municípios, 2018. Disponível em: https://www.ibge.gov.br/geociencias/organizacao-do-territorio/estrutura-territorial/15761-areas-dosmunicipios.html?=\&t=sobre. Acesso em 25 out. 2019

IBGE, Instituto Brasileiro de Geografia e Estatística. Enciclopédia dos municípios Brasileiros. Rio de Janeiro, 1959. Disponível em: https://biblioteca.ibge.gov.br/visualizacao/livros/liv27295_27.pdf. Acesso em 10 ago. 2019. 
IBGE, Instituto Brasileiro de Geografia e Estatística. PIB por município, 2016. Disponível em: https://www.ibge.gov.br/estatisticas/economicas/contas-nacionais/9088-produto-interno-bruto-dosmunicipios.html?t=pib-por-municipio\&c=1100023. Acesso em 10 ago. 2019.

INEP, Instituto Nacional de Estudos e Pesquisas Educacionais Anísio Teixeira. Education at a Glance 2018. Disponível em:

http://download.inep.gov.br/acoes_internacionais/eag/documentos/2018/EAG_Relatorio_na_integra.pdf. Acesso em: 12 de out. 2019.

IPHAN, Instituto do Patrimônio Histórico e Artístico Nacional. São João del-Rei (MG), c2014. Disponível em: <http://portal.iphan.gov.br/pagina/detalhes/375/>. Acesso em 12 de out. 2019.

MARINHO, Emerson; NETO, Paulo de Melo Jorge. Gastos públicos e condições de vida nos municípios do estado do Ceará. Revista de administração pública, v. 33, n. 3, p. 139-160, 1999.

MINAS GERAIS, Governo do Estado de. A Capital, 2019. Disponível em:

https://www.mg.gov.br/conteudo/conheca-minas/turismo/capital. Acesso em: 10 ago. 2019.

MYRDAL, Gunnar. Teoria econômica e regiões subdesenvolvidas. 2. ed. Rio de Janeiro: Saga, 1957.

MYRDAL, Gunnar. Teoria econômica das regiões. Saga, 1968.

NAÇÕES UNIDAS. A Onu e o Desenvolvimento. c2019. Disponível em: https://nacoesunidas.org/acao/desenvolvimento/. Acesso em 13 abr. 2019.

NAÇÕES UNIDAS. Novo relatório da ONU avalia implementação mundial dos Objetivos de Desenvolvimento do Milênio (ODM), 6 jul. 2015. Disponível em: https://nacoesunidas.org/novorelatorio-da-onu-avalia-implementacao-mundial-dos-objetivos-de-desenvolvimento-do-milenio-odm/. Acesso em: 27 nov. 2019.

PEREIRA, Honório Nicholls. Permanências e transformações nas cidadesmonumento: teatro social e jogos de poder (São João Del Rei: 1937-1967). Salvador, 2009. Tese de Doutorado. Dissertação (Mestrado). Programa de pós-graduação em Arquitetura e Urbanismo da Universidade Federal da Bahia.

PNUD, Programa das Nações Unidas para o Desenvolvimento. O que é IDH?. c2019. Disponível em: http://www.br.undp.org/content/brazil/pt/home/idh0/conceitos/o-que-e-o-idh.html. Acesso em: 30 de mar. de 2019.

PNUD. Informe Sobre Desarrollo Humano México 2002, 2003. Disponível em: http://biblioteca.hegoa.ehu.eus/downloads/13994/\%2Fsystem\%2Fpdf\%2F568\%2FInforme_sobre_Desarr ollo_Humano_Mexico_2002.pdf. Acesso em 15 set. 2019

PORTAL BRASIL. Índice Nacional de Preços ao Consumidor - INPC, c2019. Disponível em: https://www.portalbrasil.net/inpc.htm. Acesso em: 18 out. 2019.

RAIHER, Augusta Pelinski; DE LIMA, Jandir Ferrera. Desenvolvimento humano municipal no sul do Brasil: evolução recente e o círculo vicioso da pobreza. Acta Scientiarum. Human and Social Sciences, v. 36, n. 2, p. 147-154, 2014.

SANTOS, Bruno Henrique dos. A formação socioespacial de São João del-Rei/MG e o processo de regionalização do campo das vertentes. São João del-Rei, Dissertação de Mestrado, Programa de Pósgraduação em Geografia da UFSJ, 2017. 
SEN, Amartya. A ideia de justiça. Editora Companhia das Letras, 2011.

SEN, Amartya. Desenvolvimento como liberdade. Editora Companhia das Letras, 2018.

SILVA, Mariângela Amaral e; MARION FILHO, Pascoal José; CORONEL, Daniel Arruda. A ORIGEM E A EVOLUÇÃO RECENTE DAS DESIGUALDADES REGIONAIS ENTRE COREDES (1990-2003). Fundação de Economia e Estatística (FEE), Porto Alegre, 2006. Disponível em:

<https://www.fee.rs.gov.br/3eeg/Artigos/m01t02.pdf>. Acesso em: 17 de out. de 2019.

SOLOW, Robert M. A contribution to the theory of economic growth. The quarterly journal of economics, v. 70, n. 1, p. 65-94, 1956. Disponível em: https://academic.oup.com/qje/articleabstract/70/1/65/1903777. Acesso em: 5 jul. 2019.

SRE/SJDR, Secretaria Regional de Ensino/São João del-Rei. EDUCAÇÃO Integral e Integrada Designação, 2019. Disponível em: https://sresjdelrei.educacao.mg.gov.br/index.php/18-designacao/399secretaria-de-estado-de-educacao-anuncia-expansao-da-educacao-integral. Acesso em: 15 de out. de 2019.

TESOURO NACIONAL. Contas Anuais - FINBRA, c2019. Disponível em:< http://www.tesouro.fazenda.gov.br/contas-anuais> Acesso em: 8 de maio 2019.

TRAVASSOS, Claudia; VIACAVA, Francisco. Acesso e uso de serviços de saúde em idosos residentes em áreas rurais, Brasil, 1998 e 2003. Cadernos de Saúde Pública, v. 23, p. 2490-2502, 2007.

UFSJ, Universidade Federal de São João del-Rei. A Inserção da UFSJ em seu Contexto Regional, 13 out. 2007. Disponível em: https://ufsj.edu.br/aufsj_contexto.php. Acesso em: 5 de out. 2019.

Recebido: 05/03/2021

Aceito: $14 / 08 / 2021$

Publicado: Dezembro de 2021 